to bear in a sufficient degree on water wheels within the ordinary limits of diameter.

The author produced instances of the desired pressure engine, one of which was constructed about forty years ago, in Derbyshire-and which he believed was still at work in the Alport Mines, to which it was removed from its original situation. The cylinder was, he believed, 30 inches in diameter. In 1S41, Mr. John Taylor advised the application of another and more powerful engine, at the Alport Mines, which was made under his (Mr. Glyn's) direction, at the Batterby Ironworks, in Derbyshire. This was the most powerful engine that had been made. The cylinder was 50 inches in diameter, and the stroke 10 feet. It was worked by a column of water of 132 feet in height, so that the proportion of power to act on it, was as the area of a piston to that of the plunger-namely, 1963 to 1385 , or fully 70 per cent. 'The superintendent of the machinery assured him, that the engine had never cost them $\mathfrak{E} 12$ a year since it was erected. Its usual speed was about 5 strokes per minute; but it was capable of working at 7 strokes per minute, without any concussion in the descending column, the duty actually done being equal to 163 horse power:-Area of plunge, 9.621 feet $\times 10$ feet $\times 7$ strokes $=673.41 . \quad 673.41 \times 62.5 \times$ $132=5 \frac{5}{3} \frac{5}{3} \frac{5}{5} \frac{5}{6} \frac{32}{6}=163$ horse power.

The author concluded by remarking that, in this case, as in all others, when water acts by its gravity, or pressure, those machines do the best work, when the water enters the machine without shock, or impulse, and quits it without velocity. 'They thereby obtain all the available power that the water will yield with the least loss of effect; and this result is best accomplished, by making the pipes and passages of sufficient and ample size, to prevent acceleration of the hydrostatic column.

Lond. Athenæum, Aug. 1848.

\title{
On a New Element of Mechanism.
}

Read before the British Association for the Advancement of Science.

By Mr: R. Roвerts.

The writer explained the construction of a contrivance, by which he effected, in a very simple inanner, movements for which more complicated mechanism was frequently employed. The model consisted of a steel stock shaft, on which were fitted two brass disks, in such a way as to be kept steady. One of the disks had eleven teeth, rounded at the top and bottom, in its circumference, and was placed on the body of the shaft. The other disk, which was rather the larger, was in the eccentric position of the shaft, with its face to that of the toothed disk. The plain disk had four studs rivetted into it, at equal distances from each other, and at such distances as to admit of their being brought successively, by the revolution of the eccentric, to the bottom of the hollows in the toothed disk. The following movements may be effected by this model: viz., if the shaft be held stationary, and the disks be made to revolve upon it, one of the disks will make twelve revolutions whilst the other only makes eleven. Again, if the toothed disk be held 
whilst the shaft be made to revolve $t$ welve times, the plain disk will revolve, in the same direction, one revolution only; and if the plain disk be held, the toothed disk will perform one revolution, in the contrary, for eleven revolutions of the shaft. It would be evident that almost any other number of revolutions may be produced, by employing a smaller number of studs, not fewer than three, which will not divide the number of teeth in that disk. The idea of this novel element in mechanics, was suggested to Mr. Roberts by a dial movenient in an American clock.

Ibid.

\section{Applications of Gutta Percha.}

Read before the British Association for the Advancement of Science.

By Mr. F. W HIshaw.

Mr. Whishaw read a paper, giving an explanation of the various applications of Gutta Percha; numerous specimens of which, in the shape of thread, cord, tubular staves, driving bands, constables' staves, sticks, whips, inkstands, medallions, shields, water buckets, stereotype plates, and almost every other description of article, both useful and ornamental, were present.

The paper, after stating that gutta percha was the concrete juice of a large tree of the same name, abounding in Borneo, \&c., obtained by tapping the tree periodically, by the Malays, stated that its introduction into this country was purely accidental; Dr. Montgomery having transmitted the first sample of it to the Society of Arts, in 1843, at which time he (Mr. Whishaw) was Secretary to that Society. The first articles of use marle of gutta percha, in this country, were laid before the Society of Arts in 1844, and consisted of a lathe-band, a short length of pipe, and a bottle-case, which he had himself made by hand, having caused the concrete substance to become sufficiently plastic, by immersing it in hot water. He also produced casts from medals, which attracted considerable attention at the time, and surgical instruments were soon after made of this new material. It was also adapted to commercial uses; and, from the period mentioned, to July 11 th, in the present year, between 600 and 700 tons had heen imported for the Gutta Percha Company. From 20 to 60 tons were now regularly imported every month.

Contrary to the general opinion, that gutta percha is a simple, hydrogenous substance, Mr. Crane (chemist to the Gutta Percha Com. pany) found it, in its ordinary state, to consist of at least two distinct materials, besides a notable proportion of sulphur-viz., 1. A white matter, gutta percha in its pure state; 2. A substance of a dark brown color. Various experiments were made, to ascertain its strength when mixed with other matters, and also, as to what pigments would mix with it, without rendering it brittle, or deteriorating its qualities.From these it appeared, that the only pigments that could altogether be relied on, to be used with gutta percha, were orange lead, rose pink, red lead, vermilion, Dutch pink, yellow ochre, and orange chrome.Under the influence of heat and pressure, gutta percha would spread 